\title{
Computer Models of Concrete Structures
}

\section{Modèles informatiques pour les structures en béton}

\author{
Finite-Element-Modelle von Betontragwerken
}

\author{
Vladimir ČERVENKA \\ Dr. Eng. \\ Czech Techn. Univ. \\ Prague, Czechoslovakia \\ V. Cervenka received his \\ Ph.D. degree in 1970 at the \\ University of Colorado in \\ Boulder. He is active in the \\ research of concrete struc- \\ tures at the Czech Technical \\ University in Prague and at \\ Stuttgart University.
}

\author{
Rolf ELIGEHAUSEN \\ Prof. Dr. \\ University Stuttgart \\ Stuttgart, Germany \\ R. Eligehausen received his \\ Dr. Ing. degree in 1979 in \\ Stuttgart. Since 1984 he is \\ professor for fastening \\ technique at the Institute of \\ Civil Engineering Materials \\ at Stuttgart University.
}

\author{
Radomír PUKL \\ Dr. Eng. \\ Czech Techn. Univ. \\ Prague, Czechoslovakia \\ R. Pukl received his Ph.D. \\ degree in 1985 at the Czech \\ Technical University in Pra- \\ gue. He works in the field of \\ computational mechanics at \\ the Czech Technical Univer- \\ sity in Prague and at Stutt- \\ gart University.
}

\section{SUMMARY}

The application of the nonlinear finite element analysis of concrete structures as a design tool, is discussed. A computer program for structures in plane stress state is described and examples of its application in the research of fastening technique, and in engineering practice, are shown.

\section{RÉSUMÉ}

On discute ici de l'application, en tant qu'outil de dimensionnement, de l'analyse non-linéaire par éléments finis, et ceci dans le cadre des structures en béton armé. Un programme pour des structures en état plan de contrainte est décrit, ainsi que ses applications dans le domaine de la recherche et de le pratique de l'ingénieur.

\section{ZUSAMMENFASSUNG}

Die Anwendung der nichtlinearen Finite Elemente Analyse auf Betontragwerke als Entwurfswerkzeug wird diskutiert. Ein Programm für die Konstruktionen im ebenen Spannungszustand wird beschrieben und Beispiele für die Anwendung in der Forschung der Befestigungstechnik und in der Ingenieurpraxis werden vorgestelit. 


\section{INTRODUCTION}

Due to the complexity of concrete behavior under various states of stress, the development of rational design models is a difficult task. This development is treated in detail by many authors at this Colloquium. Schlaich explains why the design process requires several "design models" , because more general approaches are too complex for designers and serve as "research models". MacGregor and Marti show the recent development of engineering design models which have evolved from simple equilibrium truss analogy into more consistent models which take into account strain fields and the constitutive laws. Further refinement of these models would require better constitutive laws, better modeling of the multiaxial stress states and better discretization. Then, of course, the simple models turn into the complex ones. This complexity can be handeled in a rational manner by the finite element method. FE models of concrete structures have been in development for over 20 years and are now at a stage, that thay can be used as design tools, as demonstrated by Scordelis in this Colloquium. The authors believe, that models of all levels of sophistication have their place in design provided that they are rationally based and verified in practice. It is up to the designer to choose the appropriate model under the given circumstances. However, a unified approach for all design models should be accepted which will assure the compatibility between various levels of sophistication. This is also true for safety concepts, which should be extended to the FEM design models. It should be noted, that the CEB has started a significant effort in this respect. It is the purpose of this paper to demonstrate the capabilities of the non-linear finite element method for the analysis of concrete structures and to show its application as an advanced design model. It will be done on the example of the program SBETA, which was developed by the authors. However, we shall first provide a brief summary of the currently used computational models.

\section{CONSTITUTIVE MODELING}

The performance and quality of the non-linear finite element analysis depends on all of it's basic components: constitutive model, finite element discretization, solution technique. Of these components, the constitutive model is the most important since it determines the ability of the analysis to model the specific properties of concrete structures. Therefore, we shall make a brief critical overview of some constitutive models which are important for the development of design models.

In the early stages of development two main classes of constitutive models of concrete were used, namely, the models based on the theory of plasticity and the models based on the nonlinear elasticity (hypoelasticity). Each of these approaches can well describe some features of concrete behavior, while other features are modeled poorly. The theory of plasticity is suitable for metals but un-suitable for concrete, which is a quasi-brittle material. Hardening plasticity can model the nonlinear behavior of concrete in compression [13], but cannot model cracking and softening behavior. In that sense, the range of application of the plasticity models in concrete structures is restricted to pre-peak compression. Therefore, the plasticity theory was often combined with the brittle-fracturing model for tension $[9,2]$.

Hypoelastic models have been successfully used by many authors [1,15,19]. The orthotropic hypoelastic models have been criticized for their lack of objectivity [3] in the case of rotation of strain fields. Inspite of this, they have the ability to cover a wide range of the concrete behavior, i.e. tension and compression, cracking, and softening.

All of the models described above have typically been used within the "smeared material" approach with a local formulation of the stress-strain laws, where stresses are related to strains at a material point. This "local concept" cannot describe the size effect which is evident from experiments. Introduction of the size effect can be done by means of the "non-local concept", 
in which the stresses are related to strains in a certain representative volume $[4,5]$.

Cracking has a dominant effect on the non-linear behavior of concrete structures. Therefore, much research is devoted to improve the fracturing model of concrete, as reported recently during a workshop at Torino [7]. The subject is treated in detail in the papers of Hillerborg and König presented at this Colloquium. It is generally accepted that the tensile toughness of concrete is a material property. It is caused by tension softening response after cracking and is characterized by the fracture energy parameter $G_{f}$. In finite element analysis there are two kinds of crack models. In a discrete crack model, a crack is formed by disconnecting the nodes of the finite element mesh and introducing a new boundary. After cracking, re-meshing must be performed in order to adjust the element boundary to the crack path $[8,17,18]$ unless the crack follows a predefined path along the existing element mesh. The softening is modelled by stress-crack-opening law of the crack interface. In a smeared crack model, a band of parallel cracks is formed in the entire element volume under consideration (e.g. volume associated with the integration point). The softening of the crack band is derived from the fracture energy parameter $[6,10]$. Thus, both approaches have the same theoretical basis and in many cases should give similar results.

A smeared-crack model based on the orthotropic hypoelastic law can have two basic forms [11]. In a rotated crack model, the axes of principal stress and strain coincide. Rotation of the principal strain axes causes the rotation of material axes (which are coincident with cracks). In a fixed-crack model, the crack direction is determined upon crack initiation, and is kept fixed during the subsequent analysis.

In the fixed-crack model, the crack plane can be subjected to a shear strain and its shear stiffness, representing the aggregate interlock and the dowel action of reinforcement, should therefore be included. This is accomplished by many analysts by means of a shear retention factor, which assignes a constant reduced shear stiffness to the cracked concrete. However, the solution of shear failures is extremely sensitive to the shear retention factor and therefore the use of a constant shear retention factor is not recommended [20]. Improved performance is obtained by decreasing the crack shear stiffness as a function of crack width [11].

Both discrete and smeared crack models have their own merits. The discrete cracks are appropriate for modeling the fracture of plain concrete with one distinct crack, while smeared cracks are more suitable for reinforced concrete. The advantage of the smeared crack model is that it can cover a variety of crack situations ranging from finely distributed cracks in reinforced concrete to a single discrete crack, without modification of the element mesh, as will be demonstrated in this paper.

All previously described smeared models can be classified as macroscopic models. They directly relate stress and strain components. For general stress states and load path situations, they usually require a large number of material parameters. Further improvement can be expected from a microplane model $[5,14]$. This is a microstructural model in which the material properties, such as the material stiffness matrix, are integrated from elementar behavior of microplanes. It is a three-dimensional model which is unique for all stress states and a wide range of behavior, including cracking, softening, and dilatancy. It is the most general model developed so far for use in the finite element analysis. It is, however, more demanding on computer capacity because the microplanes introduce another level of discretization. The application of the microplane model is presented in a paper by Eligehausen and Ozbolt at this Colloquium.

The above overview is only a brief outline of the present practice with respect to constitutive modeling of concrete structures. Other aspects of FE modeling, such as the method of finite element discretization and solution techniques, shall not be treated here. The interested reader 


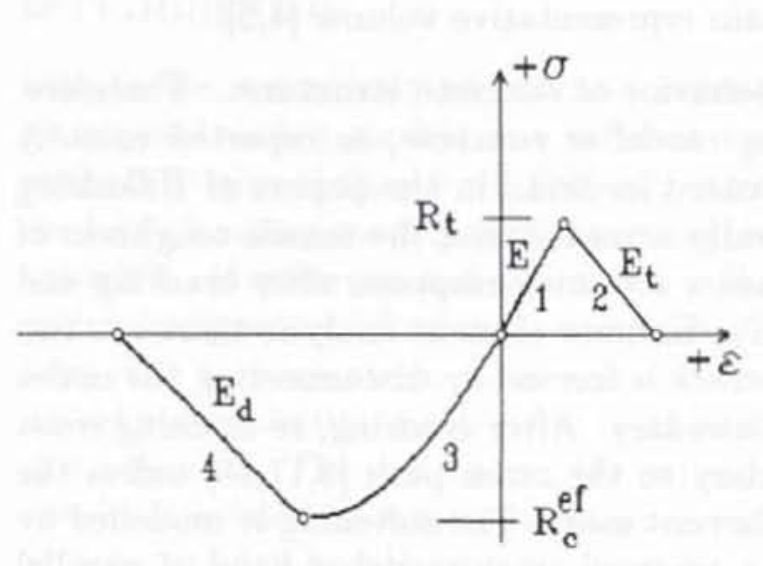

1a. Effective stress-strain law.

Fictitious Crack:

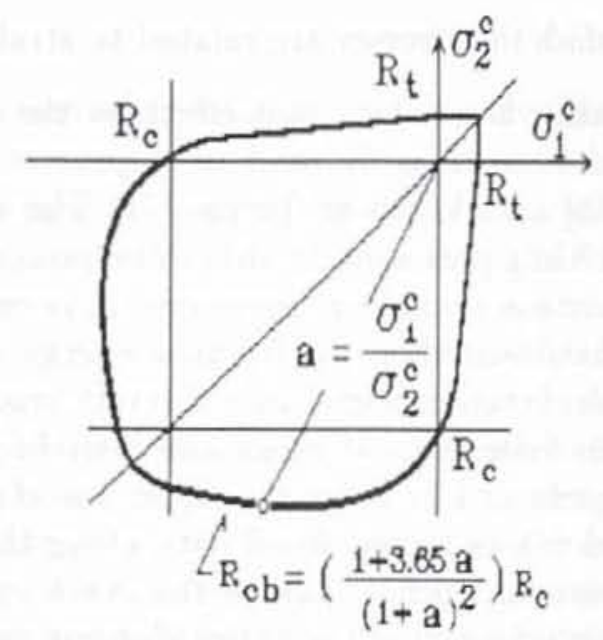

1b. Biaxial failure function.
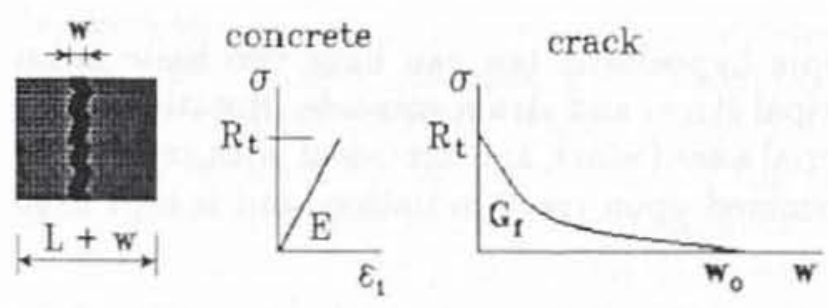

$G_{f}=\int_{0}^{w_{0}} \sigma d w$

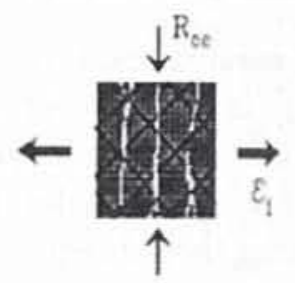

Smeared Cracks:
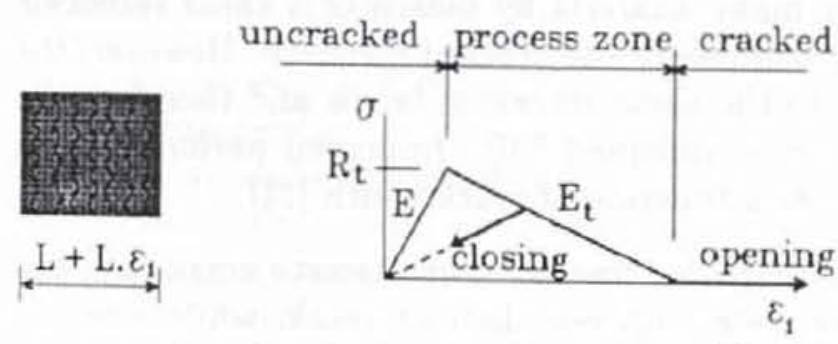

1c. Fracturing in smeared model.

$$
\begin{aligned}
\frac{1}{E_{t}} & =\frac{1}{E}\left(1-\frac{\lambda}{L}\right) \\
\lambda & =\frac{2 E G_{f}}{R_{t}^{2}}[\mathrm{~m}]
\end{aligned}
$$

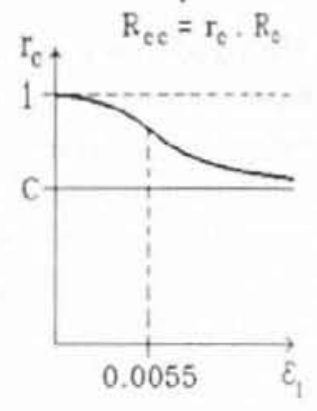

1d. Compressive strength reduction due to cracking.

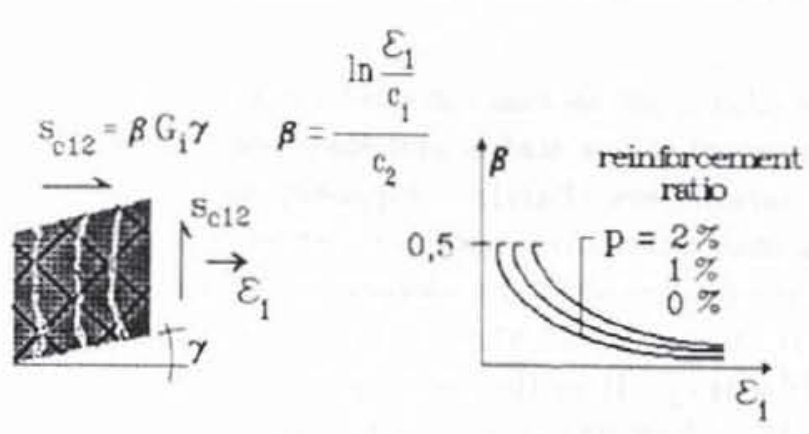

le. Shear stiffness of cracked concrete.

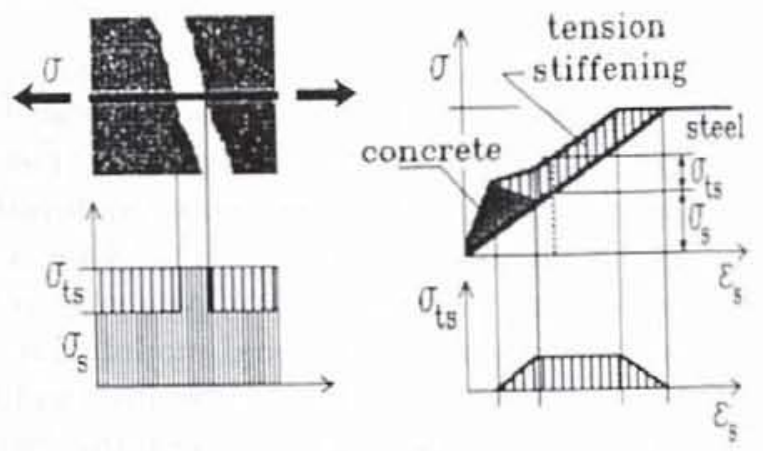

1f. Tension stiffening.

Fig.1 Constitutive model in program SBETA. 
can find a number of publications on this subject.

\section{PROGRAM SBETA}

Advances in constitutive modeling of concrete and the availability of efficient computers make it possible to produce programs for non-linear finite element analysis which can be used as design tools. Such a program was recently developed by the authors at the Institut für Werkstoffe im Bauwesene at the University of Stuttgart in cooperation with the Building Research Institute of the Czech Technical University in Prague. An overview of the program and examples of it's application in research and engineering practice are presented.

The program SBETA [12] is designed for the analysis of reinforced concrete structures in the plane stress state. It can predict the response of complex concrete structures, with or without reinforcement, in all stages of loading, including failure and post-failure. It can serve as a research tool for the simulation of experiments and for the analysis of experimental results. In design practice it can be used to optimize the geometry and reinforcement detailing and to calculate the load-carrying capacity of structures. It can be also used for the diagnosis of the causes of structural damage or failure.

The constitutive model of the program SBETA is summarized in Fig.1. It is based on the smeared material approach using non-linear elasticity and non-linear fracture mechanics. The behavior of concrete is described by a stress-strain diagram, Fig.la, which is composed of four branches: non-linear loading in compression, linear loading in tension, and linear softening in both tension and compression. The parameters of this diagram are adjusted in the following way: The peak stress $R_{c}^{e f}$ is taken from the biaxial failure function of Kupfer, Fig.lb, and the softenning modulus in tension $E_{\mathrm{t}}$ is calculated according to the crack band theory of Bazant [6], Fig.1c.
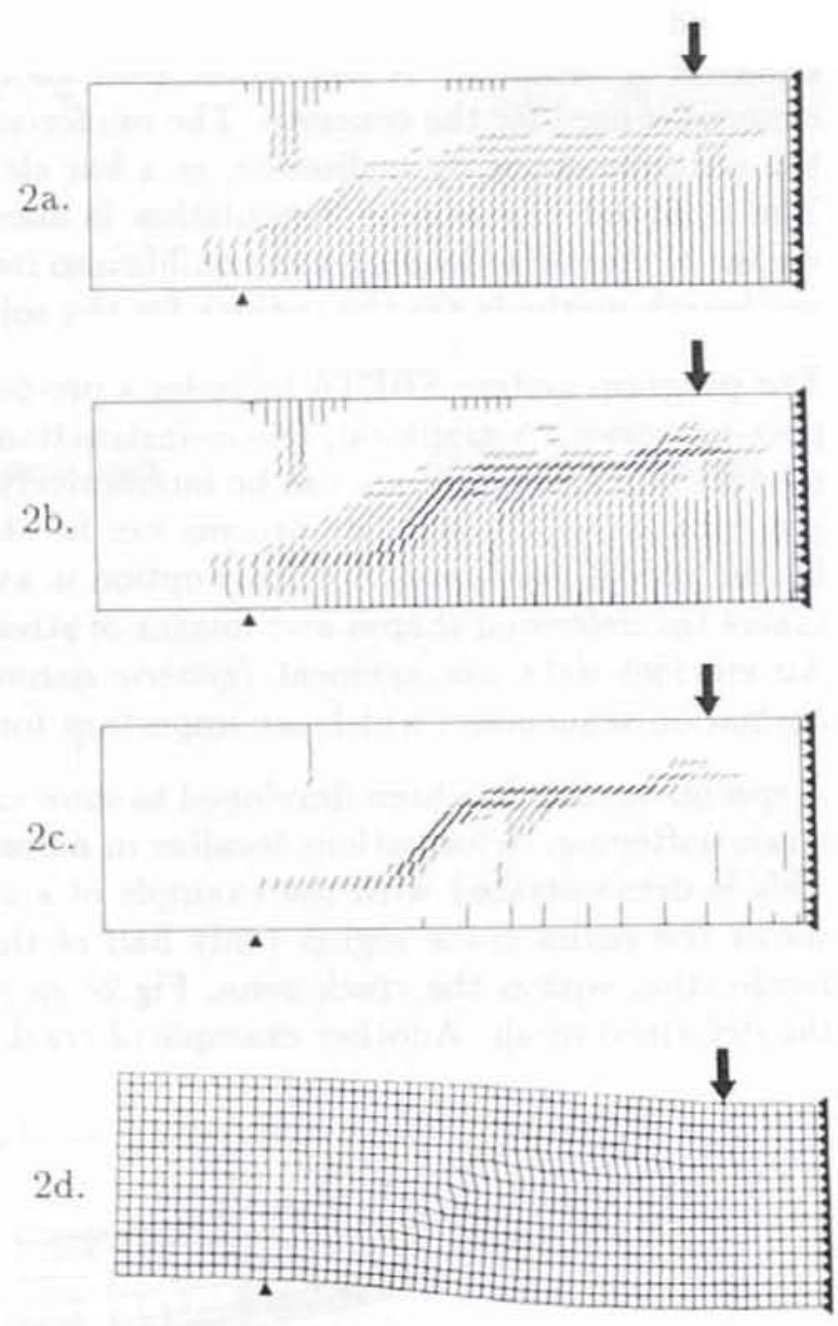

Fig.2 Crack localization in shear.

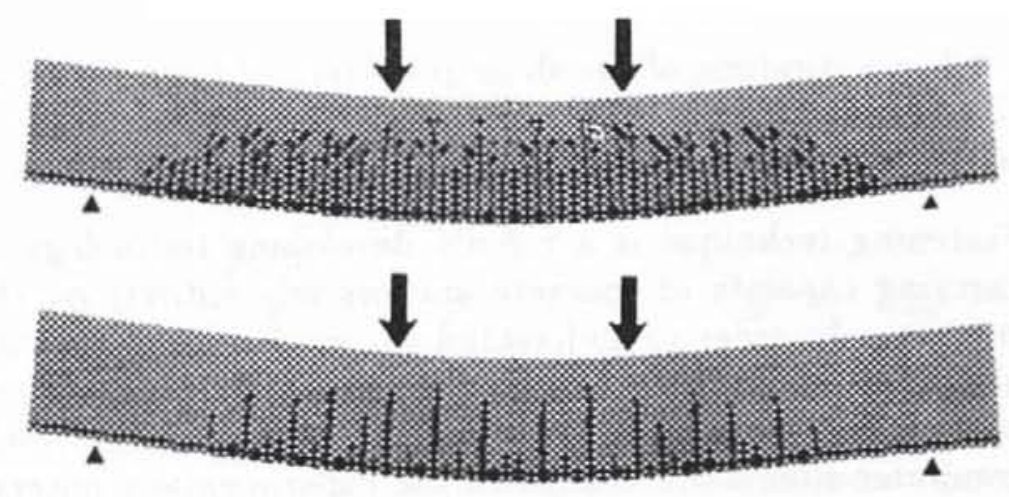

Fig. 3 Crack localization in bending. 
The modelling of cracked reinforced concrete includes the shear resistance of cracks, Fig.le, reduction of compressive strength in the direction parallel to the cracks, Fig.1.d and the effect of tension stiffening, Fig.1f. Fixed and rotated crack models are implemented. Reinforcement behavior is bi-linear. A monotonic load history is assumed. A four-node quadrilateral finite element is used for the concrete. The reinforcement can be included either smeared, as a part of the concrete element, or discrete, as a bar element passing through the quadrilateral element. The updated Lagrangean formulation is adopted. The non-linear solution is performed by means of step-wise loading and equilibrium iteration within a load step. Newton-Raphson and arc-length methods are the options for the solution strategy.

The program system SBETA includes a pre-processor, FEM solution program, and an efficient post-processor. A graphical, macro-instruction-based pre-processor generates the FE numerical model. The FEM program can be interactively controlled and runs in several levels of real-time graphics. Thus, the solution process can be observed and solution parameters can be adjusted by the user if necessary. A restart option is available. The dialog-oriented post-processor generates the deformed shapes and images of stress, strain and damage fields (cracking, crushing). An efficient data management (generic names, profile files, etc.) enables the generation of animation sequences, which are important for the detection of failure modes.

A special method has been developed to show crack-localization in the smeared material. Due to strain-softening, deformations localize in narrow bands which indicate the main failure cracks. This is demonstrated with the example of a shear failure of a beam without stirrups. Fig.2a shows the entire crack region (only half of the beam was analyzed), Fig. $2 b$ indicates strain. localization within the crack zone, Fig.2c shows the location of the failure crack, and Fig.2d the deformed mesh. Another example of crack-localization for bending is shown in Fig.3.

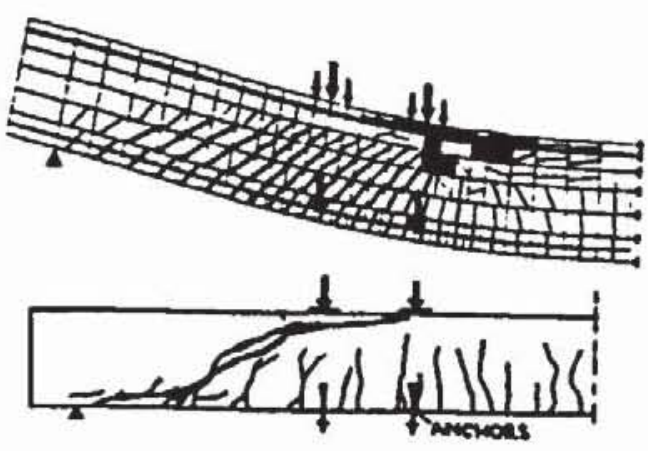

Analytical and experimental failure patterns.

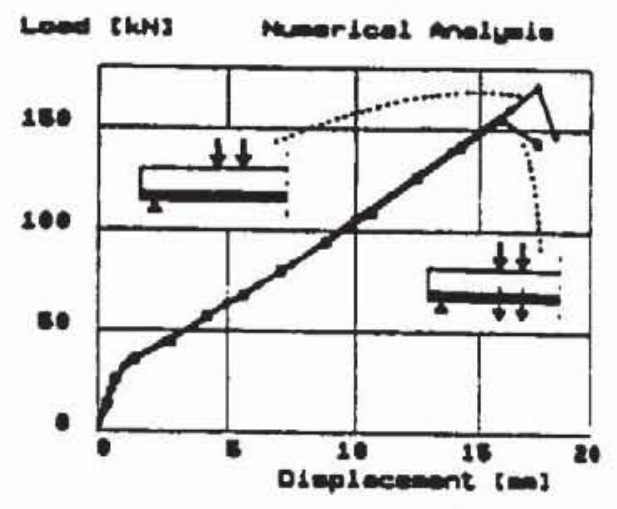

Load-displacement diagrams.

Fig.4 Analysis of the shear resistance of beams with anchors in the tensile zone.

\section{APPLICATIONS IN FASTENING TECHNOLOGY}

Fastening technique is a rapidly developing technology in the concrete industry. The loadcarrying capacity of concrete anchors rely entirely on the tensile strength and toughness of concrete. In order to understand the mechanics of anchor failure, the authors have performed a number of numerical studies which simulate experimental investigations. In one such in. vestigation [11] a beam with anchors located in the cracked zone was examined, Fig.4. The computer simulation confirmed the experimentally observed reduction of the shear resistance of beams due to the anchor loads introduced into the bottom of the beam. A similar study was conducted by Eligehausen and Kazic for T-beams, using the material model from SBETA in another program, AXIS (see paper presented at this Colloquium).

The concrete cone failure of headed anchor bolts loaded in tension was the subject of an 

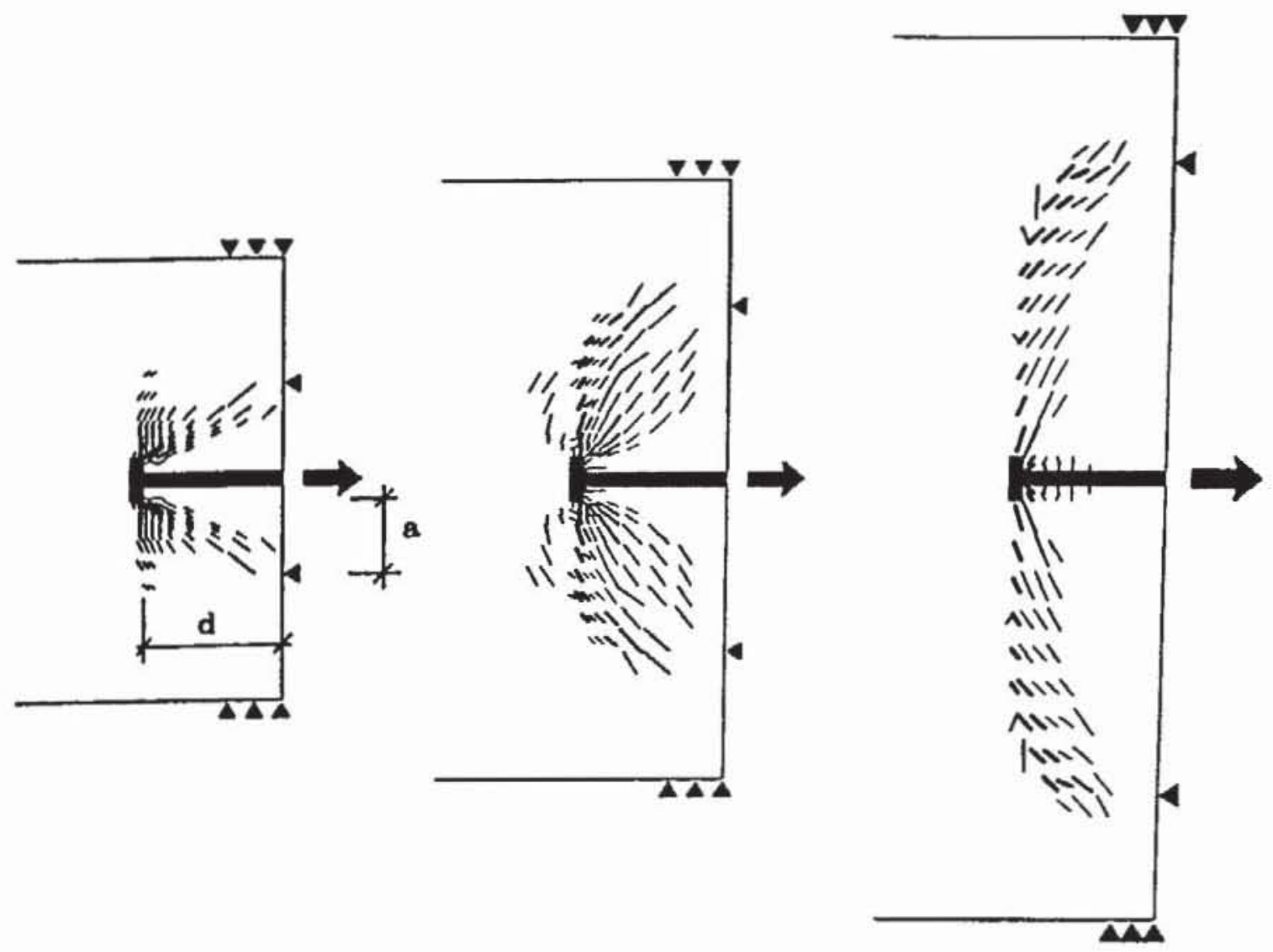

Fig.5 Failure crack patterns of pull-out tests on headed anchors with an embedment depth $d=150 \mathrm{~mm}$ and three spans $a=50,150,450 \mathrm{~mm}$.

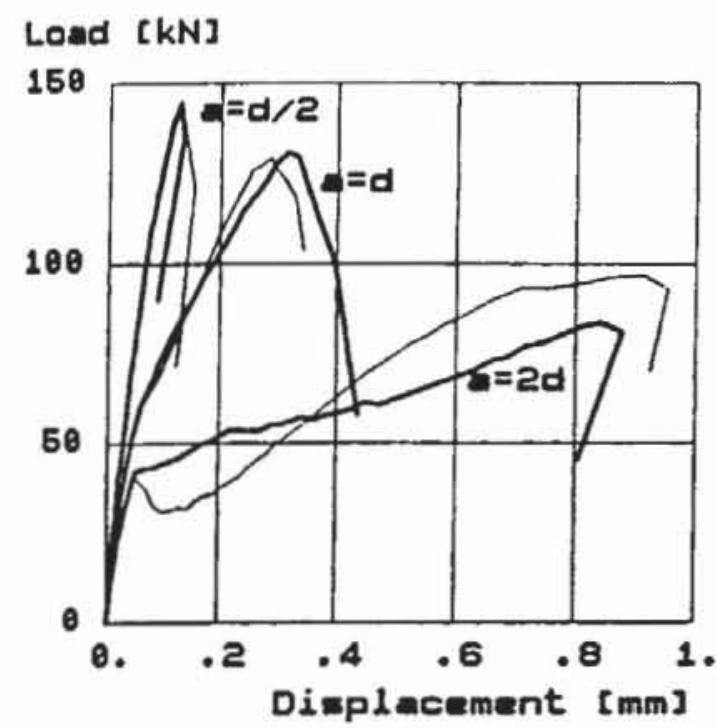

Fig.6 Load-displacement diagrams of pull-out tests for one embedment depth $d=150 \mathrm{~mm}$ and three spans $a=50,150$, $450 \mathrm{~mm}$. Thickness $\mathrm{b}=100 \mathrm{~mm}$. thin line - rotated crack model, thick line - fixed crack model

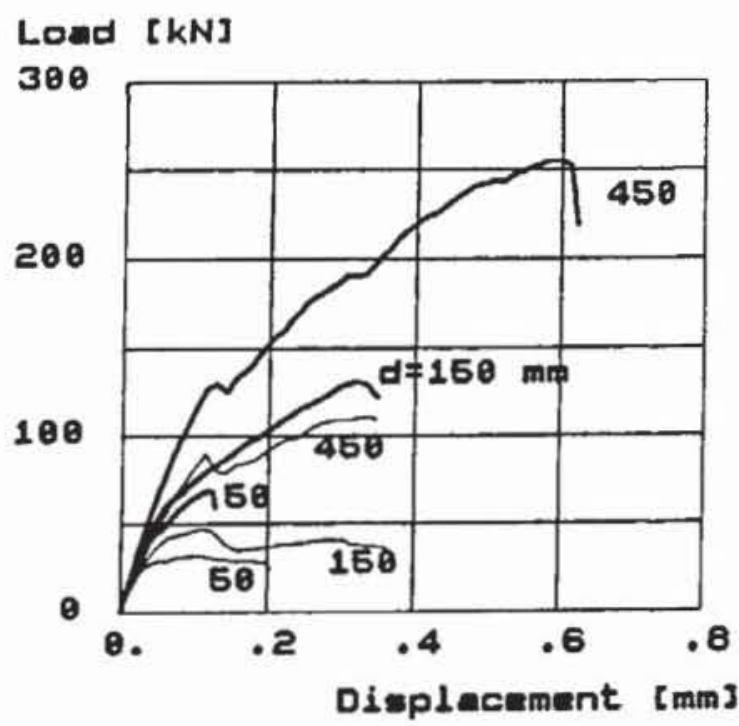

Fig.7 Load-displacement diagrams of pull-out tests for three sizes $(d=50,150$,

$450 \mathrm{~mm}$ ) and two lateral constraint conditions. Thickness $b=100 \mathrm{~mm}, a / d=1$. thin line - without constraint, thick line - with constraint 


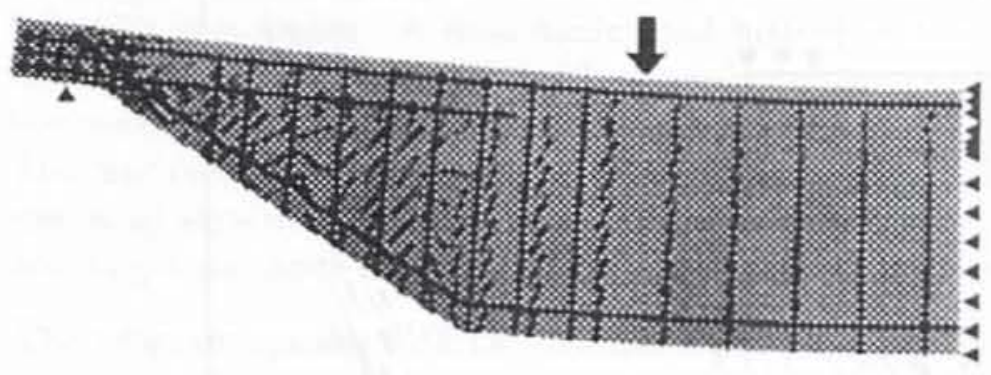

Deformed shape with crack pattern at failure.

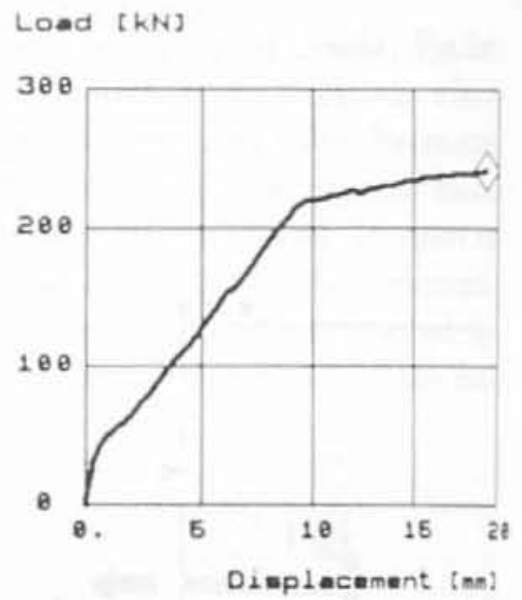

Load-displacement diagram.

Fig.8 Simulation of the ductile failure mode of a tapered beam.

Symetrical half of the beam analyzed.

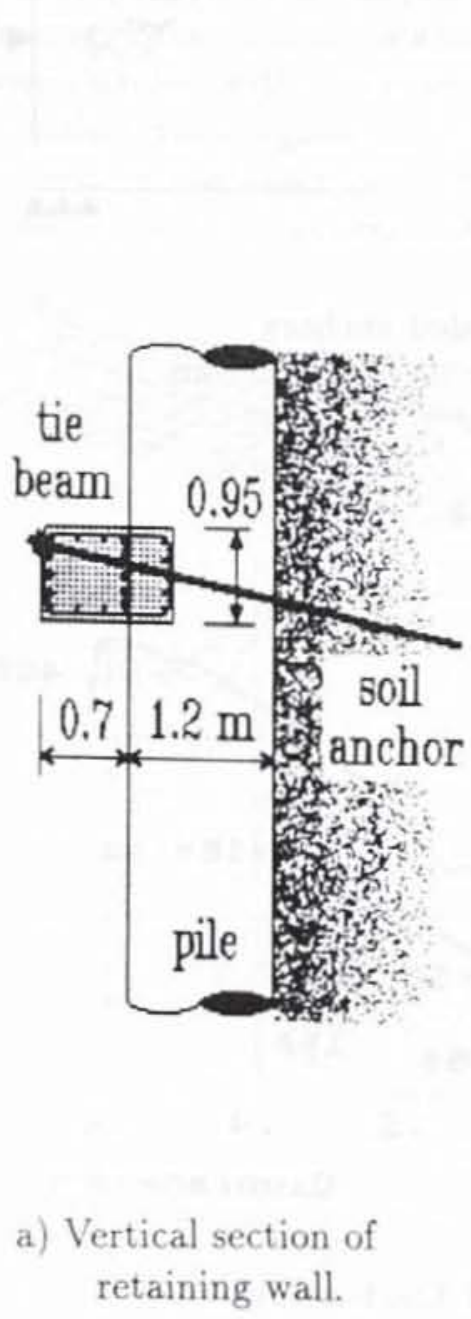

b) $\mathrm{p}=467 \mathrm{kN} / \mathrm{m}$

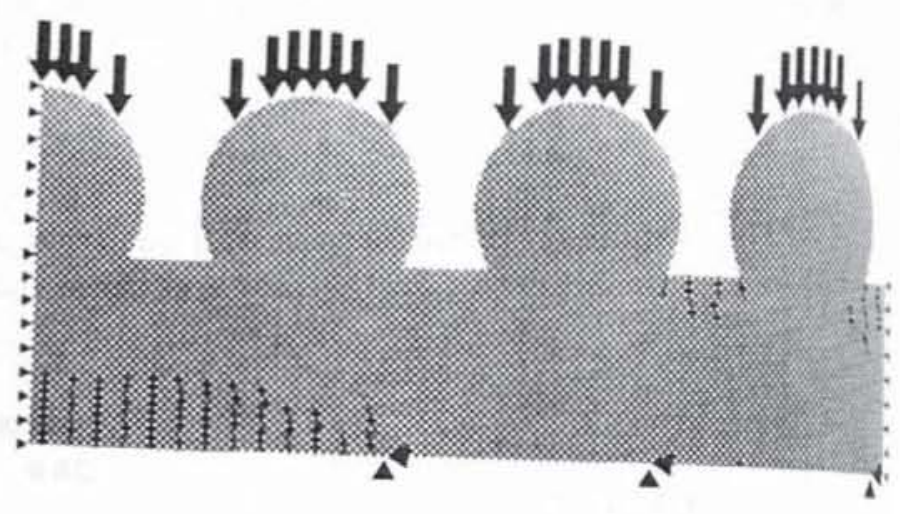

c) failure load $\mathrm{p}=974 \mathrm{kN} / \mathrm{m}$

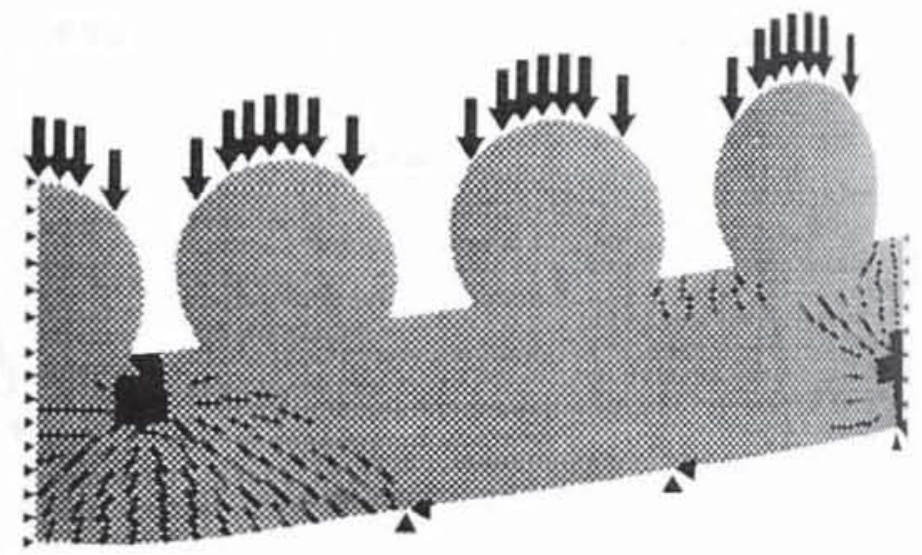

Crack and failure patterns of the tie beam. Crushed concrete shown by dark shading.

Fig.9 Simulation of the failure of tie beam supported by elastic anchors. 
international round-robin analysis organized by the RILEM Commitee on Fracture Mechanics. For this round-robin analysis, the authors have made a parameter study on various 2-D pullout tests [10]. An example from this study concerning a two-dimensional structure in plane stress state is shown here. The embedment depth $d$ and the shape ratio $a / d$ ( $a$ is the support span) were varied. Examples of the failure crack patterns for $d=150 \mathrm{~mm}$ and three different spans $a=50,150,450 \mathrm{~mm}$ are shown in Fig.5. The load-displacement diagrams for these cases are shown in Fig.6. Fig.7 shows diagrams for $a / d=1$ using three values for the embedment depth $d=50,150,450 \mathrm{~mm}$ and two assumptions for the lateral constraint (with and without lateral constraint). From these analyses, the influence of the embedment depth (size effect) could be derived. In another application, an SBETA analysis was successfully used to model the behavior of the single anchors and anchor groups subjected to transverse loading [16].

\section{APPLICATIONS IN ENGINEERING PRACTICE}

The program SBETA was used at the Prague University for the solution of several practical problems. Two examples are shown here for illustration. In the first example a precast T-beam was analyzed (Fig.8). The web is tapered and the beam is supported by an overhanging flange. The Building Research Institute of T.U. in Prague has performed experimental and numerical studies in order to optimize the reinforcement detailing. Fig. 8 shows the failure state of the final solution with a ductile failure mode due to the yielding of reinforcement.

In the second example, a tie beam of a retaining wall was analyzed. The retaining wall consists of vertical reinforced concrete cast-in-place piles which are supported by a horizontal tie beam, Fig.9. The beam is supported by earth anchors which are located between the piles. It was proposed to investigate the cases when several anchors fail. In such a case the tie beam is subjected to bending, while it is laterally constrained. Elastic supports are used to model the anchors. The maximum soil pressures were obtained for various supporting situations. Fig.9 shows two deformed shapes and crack patterns for two load stages. In the failure stage, concrete crushing is also shown. Yielding of reinforcement was also found by the analysis, but it is not shown here.

\section{ROLE OF FEM MODELS IN DESIGN OF CONCRETE STRUCTURES}

Non-linear FEM is an advanced tool for modeling the behavior of reinforced concrete structures. It's great potential lies in it's ability to work with steadily developing constitutive laws while satisfying the laws of continuum mechanics and fracture mechanics. As with any model, it is an approximation of reality. However, the degree of approximation can be controlled at all levels of the model. As demonstrated here, these models have their application in situations where simple engineering models are not adequate. In practice they have been successfully used for the design of deep beams, reinforcement detailing (D-regions) and for the diagnosis of the causes of structural failure. In research and development, they have been used for the simulation of experiments, prediction of failure modes and for the analysis of experimental results.

It should be emphasized that a non-linear FE analysis must by supported by efficient graphical tools for pre- and post-processing. Just as drawings are indispensable for structural design, graphics is indispensable for the computer analysis of structural behavior.

\section{References}

[1] BATHE, K.J., MEYER, C. - Nonlinear Analysis of R/C Structures in Practice, ASCE Journal of the Structural Division, 108 (ST7), pp. 1605-1622. 
[2] BAŻANT, Z.P., KIM, S.S. - Plastic Fracturing Theory for Concrete, ASCE Journal of the Engineenn Mechanics Division, 105 (EM3), 1979, pp. 407-428.

[3] BAŽANT, Z.P. - Comment on Orthotropic Models for Concrete and Geomaterials, ASCE Journal of be Engineering Mechanics Division, 109, No.3, June 1983, pp. 849-865.

[4] BAŽANT, Z.P., LIN, F.B. - Nonlocal smeared cracking model for concrete fracture, ASCE Jouraal of the Engineering Mechanics Division, 114, 1988, pp.2493-2510.

[5] BAŻANT, Z.P., OŻBOLT, J. - Nonlocal microplane model for fracture, damage, and size effect in structurs. ASCE Journal of the Engineering Mechanies Division, 116, No.11, Nov 1990, pp.2485-2505.

[6] BAŻANT, Z.P., OH, B.H. - Crack Band Theory for Fracture of Concrete, Mater. Struct. RILEM, Pars France, 16, 1983, pp. 155-177.

[7] CARPINTERI, A., Chairman, - International Workshop on the Application of Fracture Mechanis $w$ Reinforced Concrete, Politechnico di Torino, October 6, 1990.

[8] CARPINTERI, A., FERrARA, G., MELChIORRI, G., VAlENTE, S. - The four point shear tet of single notched specimens: an experimental and numerical analysis, ECF8 Fracture Behaviour and De sign of Materials and Structures, Ed. Firrao, The Politechnico di Torino, Oct.1-5,1990, Chameleon Prss Ltd.,London, pp.667-675.

[9] ĊERVENKA, V., GERSTLE, K. - Inelastic Analysis of Reinforced Concrete Panels. (1) Theory, (2) Er perimental Verification and Application, Publications, IABSE, Zürnch, V.31-00,1971, pp 32-45, and V s? II,1972, pp.26-39.

[10] CERVENKA, V., PUKL, R., ELIGEHAUSEN, R. - FEM Simulation of Concrete Fracture, ECF8 Fracter Behaviour and Design of Materials and Structures, Ed. Firrao, The Politechnsco di Torino, Oct.1-5,19m Chameleon Press Ltd.,London, pp.667-675.

[11] CERVENKA, V., PUKL, R, ELIGEHAUSEN, R. - Computer simulation of anchoring technique in renforced concrete, Proceedings SCI-C 1990, Zell am See, Austria, 4-6 April, 1990, Ed N.Bićaní, B Mlus Pineridge Press, Swansea, U.K., pp.1-7.

[12] ĆERVenkA, V., Eligehausen, R., PUkL, R. - SBETA Computer Program For Nonlineas Finite Element Analysis of Concrete Structures, Part 1, Program Description, Part 2, User's Manual, Part Examples of Applications, Mitterlungen des Instituts für Werkstoffe im Bauwesen No 1990/1, Unversiai Stuttgart.

[13] CHEN, W.F. - Plasticity in Reinforced Concrete, McGaw-Hill, N Y , 1981.

[14] ELIGEHAUSEN, R., OŻBOLT, J. - Size effect in anchorage behavior, ECF8 Fracture Behaviout ad Design of Materials and Structures, Ed. Firrao, The Politechnıco dı Torıno, Oct.1-5,1990, Chameleon Pras Ltd.,London, pp.721-727.

[15] ELWI, A.A., MURRAY, D.W. - Nonlinear Analysis of Axisymmetnc Reinforced Concrete Structure Structural Engineering Report No.87, University of Alberta, Edmonton, 1980.

[16] FUCHS, W. - Tragverhalten von Befestigungen unter Querlast in ungerissenem Beton, Mitteilungen do Instituts für Werkstoffe im Bauwesen No.1990/2, Universität Stuttgart.

[17] HILLERBORG, A., MODEER, M., PETERSSON, P E. - Analysis fo crack formation and crack groxts in concrete by means of fracture mechanics and finite elements, Cement and Concrete Research, 6,1960 pp.773-182.

[18] INGRAfFEA, A.R., GERSTLE, W.H. - Nonlinear Fracture Models for Discrete Crack Propagation, tp $_{\text {p }}$ plication of Fracture Mechanics to Cementitious Composites, Editor: Shah, Martınus Nighoff Publisters 1985, pp. 247-286.

[19] OTTOSEN, N.S. - Constitutive Model for Short-Time Loading of Concrete, ASCE Journal of the Esfneering Mechanics Division, 105, (EM1), 1979, pp 127-141.

[20] ROTS, J G, NAUTA, P, KUSTERS, G.M.A., BLAAUWENDRAAD, J - Smeared crack approach a: fracture localization in concrete, HERON, vol.30, No.1, 1985. 